\title{
Adherence of older emergency department patients to community-based specialized geriatric services
}

\author{
Zachary MacDonald, MD*; lan G. Stiell, MD, MSc*; loanna Genovezos, BScN, MN*; \\ Debra Eagles, MD, MSc*
}

\section{CLINICIAN'S CAPSULE}

What is known about the topic?

Little is known about attendance at outpatient specialized geriatric services following recommendation by geriatric emergency management nurses in the emergency department (ED).

What did this study ask?

The study sought to examine adherence to outpatient evaluations, including barriers and facilitators to attendance. What did this study find?

Both acceptance of and adherence to outpatient specialized geriatric services in older ED patients are suboptimal.

Why does this study matter to clinicians?

Non-adherence with recommended evaluations increases the risk of poor outcomes in patients in whom geriatric syndromes are not addressed.

\section{ABSTRACT}

Objectives: Our objective was to determine emergency department (ED) patient adherence to outpatient specialized geriatric services (SGS) following ED evaluation by the geriatric emergency management (GEM) nurse, and identify barriers and facilitators to attendance.

Methods: We conducted a prospective cohort study at two academic EDs between July and December 2016, enrolling a convenience sample of patients $\geq 65$ years, seen by a GEM nurse, referred to outpatient SGS, and consented to study participation. We completed a chart review and a structured telephone follow-up at 6 weeks. Descriptive statistics were used.

Results: We enrolled 103/285 eligible patients (86 eligible but not enrolled, 86 declined specialized geriatric referrals, and 10 declined study participation). Patients were mean age of 83.1 years, $59.2 \%$ female, and $73.2 \%$ cognitively impaired. Reasons for referral included mobility (86.4\%), cognition $(56.3 \%)$, pain $(38.8 \%)$, mood $(35.0 \%)$, medications $(33.0 \%)$, and nutrition (31.1\%). Referrals were to Geriatric Day Hospital $(\mathrm{GDH})$ programs $(50.5 \%)$, geriatric outreach $(26.2 \%)$, falls clinic
(12.6\%), and geriatric psychiatry (8.7\%). Adherence with follow-up was $59.2 \%$. Barriers to attendance included patient did not feel SGS were needed $(52.1 \%)$, inability to recall GEM consultation $(53.4 \%)$, and dependence on family for transportation (72.6\%). Home-based assessments had the highest adherence (81.5\%).

Conclusion: Adherence of older ED patients referred by the GEM team to SGS is suboptimal, and a large proportion of patients decline these referrals in the ED. Future work should examine the efficacy of home-based assessments in a larger confirmatory setting and focus on interventions to increase referral acceptance and address barriers to attendance.

\section{RÉSUMÉ}

Objectifs: L'étude visait à déterminer le respect des rendezvous (R.-V.), par les patients examinés au service des urgences (SU), pour des services spécialisés en gériatrie (SSG) externes, à la suite d'évaluations faites par le personnel infirmier spécialisé en prise en charge des urgences gériatriques (PCUG), et à cerner les obstacles au respect des R.-V. ainsi que les facteurs facilitants.

Méthode: Il s'agit d'une étude de cohortes prospective, menée dans deux SU d'enseignement, entre juillet et décembre 2016 et reposant sur un échantillon de commodité composé de patients âgés de 65 ans et plus, examinés par du personnel infirmier spécialisé en PCUG et dirigés vers des SSG externes, et ce, après obtention du consentement. Un examen de dossiers et un suivi téléphonique structuré au bout de 6 semaines ont complété la démarche. Enfin, l'étude s'appuie sur des statistiques descriptives.

Résultats: Ont participé à l'étude 103 patients admissibles sur 285 (86 sujets admissibles mais non retenus; 86 sujets écartés pour refus de demandes de SSG; 10 sujets écartés pour refus de participation à l'étude). Les patients présentaient les caractéristiques suivantes : âge moyen : 83,1 ans; femmes : $59,2 \%$; troubles cognitifs : $73,2 \%$. Les motifs de consultation comprenaient : le manque de mobilité $(86,4 \%)$, des troubles cognitifs $(56,3 \%)$, la douleur $(38,8 \%)$, des troubles de l'humeur $(35,0 \%)$, la prise de médicaments $(33,0 \%)$ et des troubles de

From the *Department of Emergency Medicine, University of Ottawa, Ottawa, ON.

Correspondence to: Dr. Debra Eagles, Department of Emergency Medicine, University of Ottawa, The Ottawa Hospital - Civic Campus, Ottawa, ON K1Y 4E9; Email: deagles@toh.ca

(C) Canadian Association of Emergency Physicians

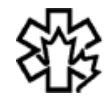

CAEP | ACMU
$2019 ; 21(5)$ 
I'alimentation (31,1\%). Les demandes de services étaient dirigées vers les hôpitaux gériatriques de jour $(50,5 \%)$, les services mobiles de gériatrie $(26,2 \%)$, les centres de prévention des chutes $(12,6 \%)$ et les services de gérontopsychiatrie $(8,7 \%)$. Les demandes ont abouti dans $59,2 \%$ des cas. Les obstacles au respect des R.-V. comprenaient la non-perception de la nécessité des SSG $(52,1 \%)$, le non-souvenir de la consultation en PCUG $(53,4 \%)$ et la dépendance des personnes âgées pour leur transport par des membres de la famille $(72,6 \%)$. Enfin, les évaluations à domicile ont obtenu le taux de plus élevé de respect des R.-V. (81,5\%).
Conclusion: Le respect des R.-V. par les patients âgés examinés au SU et dirigés vers des SSG par les équipes de PCUG n'atteint pas un degré suffisamment élevé, et une bonne proportion de ces patients refusent les demandes de services au SU. Il faudrait mener des études sur l'efficacité des évaluations à domicile dans un contexte plus large de confirmation, et cibler les interventions visant à accroître l'acceptabilité de ces demandes et à vaincre les obstacles au respect des R.-V.

Keywords: Emergency medicine, geriatric medicine

\section{INTRODUCTION}

Older persons are the highest users of the emergency department (ED), with increasingly complex needs that are poorly suited for optimal care in the busy ED environment. ${ }^{1}$ In an effort to enhance care, a geriatric emergency management (GEM) practice model has been adopted by many large EDs. ${ }^{2}$ In this model, high-risk older patients are assessed in the ED by specialized GEM nurses who perform targeted geriatric assessments. High-risk patients are those who are thought to be at increased risk of functional decline, repeat ED visits, and future hospitalization. ${ }^{3}$ Often these targeted GEM assessments identify geriatric syndromes, and recommendations are made for support services and further specialized geriatric services (SGS) in the community.

Adherence to outpatient evaluations is an important consideration for emergency physicians attempting to develop safe and appropriate disposition plans. Previous work amongst Canadian centres has shown good adherence to recommendations for outpatient specialty evaluations. ${ }^{4-6}$ Little work has been done to specifically examine the adherence in geriatric populations and describe any factors that may impact adherence. As more resources are allocated to facilitate the care of this high-risk population, it is important that we characterize the utilization of these interventions. Failure of patients to comply with community-based follow-up leads to resource waste, increases the risk of poor outcomes in patients in whom geriatric syndromes are not addressed, and precludes us from later examining the efficacy of these resource intensive assessments.

The objective of the current study is to 1) evaluate the adherence of older ED patients to recommendations for further outpatient SGS as recommended by the GEM team, and (2) characterize barriers and facilitators to attendance, with the overall goal of improving the transition of care from the ED to the community in this vulnerable population.

\section{METHODS}

\section{Design and setting}

We conducted a prospective observational cohort study at two sites of an academic, tertiary level hospital ED with combined annual visits of 170,000 in Ottawa, Ontario, between July and December 2016.

\section{The GEM program}

The GEM program was implemented in 2007 at the Ottawa Hospital to enhance the care of seniors in the ED who are at high risk of increased hospital utilization. The GEM program consists of emergency nurses with additional training in geriatrics. The service is available daily during business hours, with telephone follow-up available for eligible patients presenting outside of this time frame.

Patients may be referred to GEM by an ED physician or nurse, or through a two-phase administrative screen. The first part of the administrative screen captures patients presenting to the ED who are $\geq 75$ years of age, a resident in the local health network, not currently in long-term care, who have a previous ED visit within the last 6 months, and triaged as Canadian Triage and Acuity Scale 3, 4, or 5. Patients identified through the first phase then underwent screening with the Identification of Seniors at Risk (ISAR) tool. ${ }^{3}$ The ISAR is a 
validated tool designed to identify seniors who may benefit from a targeted assessment.

Once a referral to GEM has been made, the GEM nurse performs a focused geriatric assessment targeting cognition, mood, mobility, home function, and caregiver issues, in addition to other geriatric giants. Recommendations are made based on the specific needs of the patient and often include a referral to SGS.

\section{Study population}

We included a convenience sample of ED patients, 65 years and older, who underwent assessment by the GEM nurse and were referred for further outpatient evaluation through various SGS. We included patients assessed by both a GEM nurse in person and a GEM nurse through a telephone consultation after ED discharge.

We excluded patients if they were assessed by the GEM nurse and not referred for outpatient specialized geriatric service evaluations, did not give consent, or were subsequently admitted to hospital. Patients were consented to study participation by the GEM nurse, if they met inclusion criteria following the completion of the GEM assessments.

\section{Data collection}

Patient demographic information was obtained through the electronic medical record. Information regarding patient experience with their GEM consultation and follow-up appointment was obtained through a structured telephone follow-up interview.

Patients were contacted by telephone approximately 6 weeks after their initial ED presentation and GEM consultation. At the time of consent, patients were able to specify whether they wished to be contacted or to have a family member contacted on their behalf. Phone call attempts were made to one household, that of the patient or a designated family member. If initial contact was unsuccessful, four further attempts were made to contact them, during daytime and evening hours, on both weekdays and weekends.

Patients were read a standardized prompt, reviewing study objectives and confirming their consent to study participation. If the patient remained agreeable to study participation, a structured telephone interview (Appendix) was then completed in a standardized format.
Telephone interviews were completed with either the patient or a family member.

\section{Outcome measures}

The primary outcome was adherence to outpatient follow-up recommendations with specialized geriatric services. Adherence was determined by the proportion of patients that attended their recommended outpatient follow-up after accepting the referral in the ED. This did not include patients who declined referral for further evaluation in the ED. Outpatient follow-up recommendations were determined by analysing the GEM consultation note within the electronic records. Available specialized services included the GDH programs, the Geriatric Assessment Outreach Team (GAOT), Falls clinic, Geriatric Psychiatry Community Services of Ottawa (GPCSO), and Memory program.

The GDH provides comprehensive multidisciplinary assessment by a geriatrician and other allied healthcare professionals. In addition, short-term treatment, counseling, and education are available to patients and their caregivers to facilitate long-term care planning. The GAOT provides a focused geriatric assessment directly in the home of the patient by a nurse, occupational therapist, physiotherapist, or social worker with a focus on geriatric syndromes and in-home safety. The Falls clinic provides a multidisciplinary assessment with added emphasis on mobility and falls. GPCSO is an interdisciplinary service led by a geriatric psychiatrist with a focus on psychiatric concerns. The Memory program provides focused assessment for the diagnosis and treatment of dementia.

Secondary outcomes included patient satisfaction, and barriers and facilitators to adherence identified through our telephone follow-up. This was described both qualitatively and using a yes/no dichotomous scale. Our initial template included a five-point Likert scale; however, this was changed after initial interviews demonstrated that patients with cognitive and hearing impairments struggled with this more complicated format.

\section{Data analyses}

Simple descriptive statistics were used to determine adherence to outpatient evaluation, barriers, and facilitators to attendance and patient satisfaction. Means with standard deviations and proportions were used for continuous and categorical variables, respectively. A 
regression analysis was not performed given the small sample size of the present work.

\section{RESULTS}

Between July and December 2016, 823 targeted geriatric assessments were completed by the GEM nursing staff (Figure 1). These assessments identified 285 eligible participants, with 103 patients enrolled in the final study. Of eligible participants, 182 were excluded primarily because they declined the suggested referral to specialized services (86), or because consent for study participation was not obtained during the initial GEM assessment (86).

Baseline characteristics of the enrolled patients are summarized in Table 1 . The mean age of this population was $83.1(\mathrm{SD} \pm 1.4)$ years, with $59.2 \%$ of the population being female. The majority of patients lived at home alone $(40.8 \%)$ or with family (38.8\%). Prescription medication burden for patients was high with the average patient taking $7.9(+/-0.7)$ prescribed medications. Rate of cognitive impairment was high with $73.2 \%$ of patients being deemed impaired based on documented cognitive testing. Documented cognitive testing consisted largely of the Montreal Cognitive Assessment (MOCA) ${ }^{7}$ and Mini Mental Status Exam (MMSE), ${ }^{8}$ and, in limited cases, the Ottawa 3DY Scale ${ }^{9}$ and Mini-Cognitive Assessment (Mini-Cog). ${ }^{10}$ Cognitive impairment was defined as a MOCA less than 26, MMSE less than 25, Ottawa 3DY less than 4, and Mini-Cog less than 3.

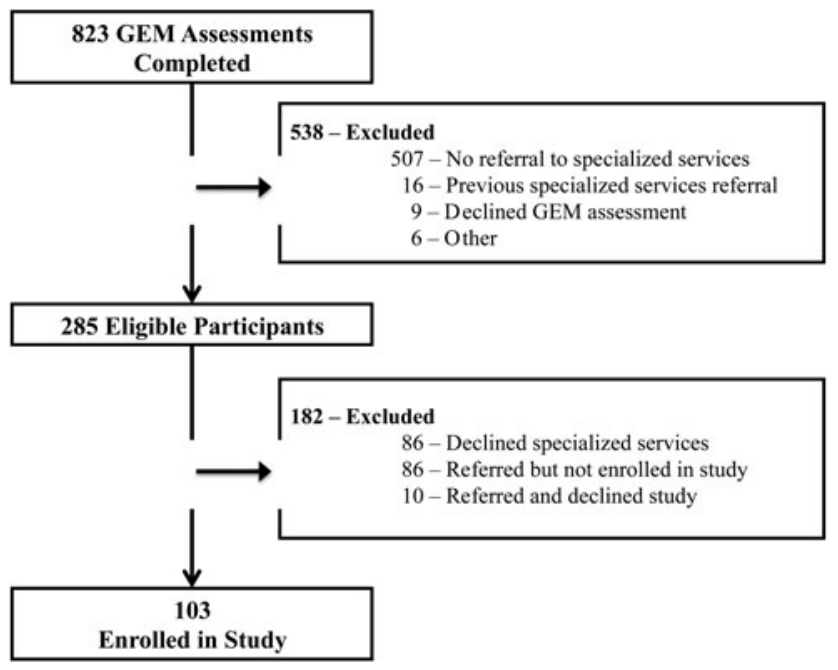

Figure 1. Study flow diagram.

\begin{tabular}{|lc|}
\hline \multicolumn{2}{|l|}{ Table 1. Patient characteristics for $\mathbf{1 0 3}$ patients with } \\
specialized geriatric services referral & $\mathrm{N}=103(\%)$ \\
\hline Characteristic & $83.1(1.4)$ \\
\hline Age, years (mean, SD) & $66-99$ \\
$\quad$ Range & $61(59.2)$ \\
Female & \\
Current living situation & $42(40.8)$ \\
Live home alone & $40(38.8)$ \\
Live in own home with family & $21(20.4)$ \\
Live in retirement residence & \\
Highest level of education & $16(15.5)$ \\
Unknown & $9(8.7)$ \\
Primary school (1-7) & $35(34.0)$ \\
Secondary school (8-12) & $30(29.1)$ \\
Post-secondary & \\
Marital status & $63(61.2)$ \\
Divorced/separated/widowed & $34(33.0)$ \\
Married/living with partner & $6(5.8)$ \\
Never married/single & $7.9(0.7)$ \\
Total \# of home prescription meds (mean, SD) & \\
Cognitive status (\%), $\mathrm{n}=71$ w/documented test* & $19(26.8)$ \\
Normal & $52(73.2)$ \\
Impaired & \\
Past medical history & \\
Hypertension & $75(72.8)$ \\
Dyslipidemia & $46(44.7)$ \\
Atrial fibrillation & $29(28.2)$ \\
Coronary artery disease & $29(28.2)$ \\
Diabetes & $28(27.2)$ \\
Stroke & $22(21.4)$ \\
Hypothyroidism & $21(20.4)$ \\
COPD & $16(15.5)$ \\
Congestive heart failure & \\
Nonecardial infarction & $3 D Y(<4)$, \\
Mini-Cog (<3) & \\
\hline
\end{tabular}

Table 2 summarizes the referral characteristics of the enrolled patients. The majority of patients were referred to the GEM nurse within the ED because of clinical concern from the bedside ED physician or nurse (71.8\%). Following a GEM assessment, patients were referred for evaluation to specialized outpatient geriatric services for multiple geriatric syndromes, including mobility (86.4\%), cognitive concerns $(56.3 \%)$ and functional decline (39.8\%). The most used SGS was the GDH program $(48.6 \%)$, followed by the GAOT (26.2\%).

Patients who agreed to a referral to SGS during their initial GEM evaluation in the ED were compliant and 


\begin{tabular}{lc|}
\hline $\begin{array}{l}\text { Table 2. Referral characteristics of } \mathbf{1 0 3} \text { patients referred to } \\
\text { specialized geriatric services }\end{array}$ & $\mathrm{N}=103(\%)$ \\
\hline Characteristic & \\
\hline GEM consultation completed in person & $79(76.7)$ \\
Reason for GEM referral (\%)* & $74(71.8)$ \\
ED physician/nurse referral & $59(57.3)$ \\
Identification of seniors at risk score > & $15(14.6)$ \\
Administrative screen & $7(6.8)$ \\
Case finding & $8(7.8)$ \\
Other healthcare professional/service & \\
Reason for outpatient referral (\%)* & $89(86.4)$ \\
Mobility & $58(56.3)$ \\
Cognitive issues & $41(39.8)$ \\
Functional decline & $40(38.8)$ \\
Pain & $36(35.0)$ \\
Mood & $34(33.0)$ \\
Medications & $32(31.1)$ \\
Nutrition & $25(24.3)$ \\
Caregiver issues & $19(18.5)$ \\
Bladder issues & $5(4.9)$ \\
Safety & \\
Place of referral (\%) & $52(50.5)$ \\
Geriatric Day Hospital & $27(26.2)$ \\
Geriatric Assessment Outreach Team & $13(12.6)$ \\
Falls clinic & $9(8.7)$ \\
GPCSO & $2(1.9)$ \\
\hline Memory program & \\
\hline
\end{tabular}

attended their recommended community-based evaluations in $59.2 \%$ of cases (Table 3$)$. The GAOT $(\mathrm{N}=25)$ had the highest rate of adherence at $81.5 \%$, which is notably the only assessment completed directly in the home of the patient. This was followed by the GDH programs $(\mathrm{N}=52)$ with an adherence of $57.7 \%$. GPCSO had the lowest rate of adherence at $22.2 \%$, primarily driven by long wait times, with many patients not having received a scheduled appointment at the time of study completion. If we consider adherence with GPCSO removed, the overall rate of appointment attendance increases to $62.8 \%$.

A structured telephone follow-up was completed with $71.8 \%$ of patients (Table 4 ), and $82.4 \%$ of those were completed with the patient directly. Only $53.4 \%$ of patients remembered their GEM assessment being completed in the ED, and only $52.1 \%$ of patients felt as though they would or did benefit from further outpatient evaluation. Amongst patients who were non-compliant, the most common cited reason was patient choice

\begin{tabular}{|c|c|}
\hline Characteristic & $N=103(\%)$ \\
\hline \multicolumn{2}{|c|}{ Overall appointment adherence (\%) } \\
\hline Attended & $61(59.2)$ \\
\hline Did not attend & $40(38.8)$ \\
\hline Unknown & $2(1.9)$ \\
\hline \multicolumn{2}{|c|}{ Adherence by place of referral (\%) } \\
\hline \multicolumn{2}{|c|}{ Geriatric Day Hospital, $n=52$} \\
\hline Attended & $30(57.7)$ \\
\hline \multicolumn{2}{|c|}{ Geriatric Assessment Outreach Team, n= 27} \\
\hline Attended & $22(81.5)$ \\
\hline \multicolumn{2}{|c|}{ Falls clinic, $n=13$} \\
\hline Attended & $6(46.2)$ \\
\hline \multicolumn{2}{|l|}{ GPCSO, $n=9$} \\
\hline Attended & $2(22.2)$ \\
\hline \multicolumn{2}{|c|}{ Memory program, $n=2$} \\
\hline Attended & $1(50.0)$ \\
\hline
\end{tabular}

\begin{tabular}{lc|}
$\begin{array}{l}\text { Table 4. Telephone follow-up call data of } \mathbf{1 0 3} \text { patients referred } \\
\text { to specialized geriatric services }\end{array}$ \\
\hline Follow-up phone call & $\mathrm{N}(\%)$ \\
\hline Contacted & $77(74.8)$ \\
$\quad$ Interview completed & $73(70.9)$ \\
$\quad$ Patient, $\mathrm{n}=73$ & $60(82.2)$ \\
$\quad$ Family member, $\mathrm{n}=73$ & $13(17.8)$ \\
Declined & $4(3.9)$ \\
Reasons for non-adherence, $\mathrm{n}=40$ & \\
$\quad$ Patient choice & $16(40.0)$ \\
Appointment pending & $4(10.0)$ \\
Never contacted & $3(7.5)$ \\
Patient uncertain/forgot & $2(5.0)$ \\
Hospital admission & $2(5.0)$ \\
Family decision & $2(5.0)$ \\
Deceased & $2(5.0)$ \\
Transportation issues & $2(5.0)$ \\
Unknown & $7(17.5)$ \\
Remembers GEM consult, $\mathrm{n}=73 *$ & $39(53.4)$ \\
Has a family doctor & $72(98.6)$ \\
Routinely see family doctor, $\mathrm{n}=72$ & $59(81.9)$ \\
Family doctor addresses all medical needs, $\mathrm{n}=59$ & $39(66.1)$ \\
Feels they will/did benefit from an outpatient evaluation & $38(52.1)$ \\
Has hard time remembering appointments & $19(26.0)$ \\
Is hard for patient to get to appointments & $33(45.2)$ \\
Cost of transportation/parking makes it hard to attend & $24(32.9)$ \\
appointments & \\
Family/friends help manage and book appointments & $39(53.4)$ \\
Family/friends help patient get to appointments & $53(72.6)$ \\
Satisfied with GEM consultation & $43(58.9)$ \\
\hline *n 73 from this point onwards unless otherwise specified. & \\
\hline
\end{tabular}


(40\%); patients were often vague and did not give specific reasons for this. Many patients experienced transportation difficulties when attending appointments (45.2\%), with the majority of patients being reliant on family/friends for both arranging appointments (53.4\%) and transportation (72.6\%).

\section{DISCUSSION}

This is the first study to explore barriers and facilitators to attendance of outpatient SGS following evaluation by a GEM nurse in older ED patients. We found that overall adherence to follow-up recommendations was poor, with a key barrier being that many patients did not perceive value or need for further specialized geriatric assessments. Home-based assessments were identified as a facilitator to adherence and should be used when possible as part of appropriate disposition planning.

\section{Comparison to existing literature}

There is a paucity of evidence surrounding adherence to post-ED outpatient follow-up in the geriatric population. What little there is, is heterogeneous with respect to patient population, reasons for referral and places of referral; thus, it is difficult to draw meaningful conclusions. Denman et al. enrolled patients $\geq 65$ years of age and reported an adherence rate of $87 \% .{ }^{11}$ Guttman et al. reported an 8-day, self-reported adherence rate of $70 \%$ for follow-up appointments recommended by an ED-based nurse discharge planning program. ${ }^{12} \mathrm{McCus-}$ ker et al. reported adherence rates of $<33 \%$ in their cohort of older patients with an ISAR score of $>1 .^{13}$ Our low adherence rate likely reflects that 1 ) our patients were high-risk (based on ISAR scores); 2) the majority had cognitive impairment; and 3) patients were referred to SGS. Our patients were screened using the ISAR, and by definition were high risk, compared with two of the studies, ${ }^{11,12}$ which did not target high-risk patients and included all persons age 65 years and older. In addition, although not described in detail, other studies included follow-up appointments to the patient's primary care practitioner, whereas our patients were referred to outpatient SGS. Older patients may be more willing to go to a physician with whom they already have an established relationship. ${ }^{14}$ Older patients may feel threatened or intimidated if they feel their cognitive ability to drive and manage their own affairs is being evaluated, and thus less likely to be accepting of specialized geriatric evaluations. ${ }^{15}$

To our knowledge, there is no published literature that examines barriers or facilitators to adherence to SGS following evaluation by a GEM team. Several studies have examined factors that influence adherence to ED recommendations, in general, with varying results. The existing literature suggests that failure to arrange appointment date prior to discharge, ${ }^{6,16-21}$ increased time from discharge to appointment date, ${ }^{22-24}$ and poor understanding of discharge instructions ${ }^{4,25,26}$ may impair patient adherence with ED follow-up recommendations. Hastings et al. found that a substantial number of geriatric ED patients had a poor understanding of their ED discharge instructions. ${ }^{27}$ The main barrier we identified was perceived lack of need for further evaluation. Many patients cited "patient choice" as their reason for failed adherence and were not able to provide more elaborate or well-articulated answers when questioned further during telephone follow-up. These findings, specific to the geriatric population, may explain why such a large proportion of older patients are not accepting of recommended referrals while still in the ED.

\section{Strength and limitations}

This study adds to the literature on adherence of older patients to outpatient follow-up following an ED visit. It provides valuable insight into barriers and facilitator to outpatient follow-up in the geriatric ED population. One of the strengths of this study lies in the prospective collection of data with good follow-up. However, the study is not without limitations. We are limited by a small sample size of a primarily urban geriatric population. In addition, the large number of patients declining initial referral in the ED was not anticipated, and thus the reasons patients decline ED referrals from the outset remain unclear. Finally, this study highlights the challenges of conducting telephone interviews with our elderly population. Over half of the patients interviewed could not recall their GEM assessment, and this is exacerbated by the high prevalence of cognitive impairment in this population. The poor recollection of these assessments makes it likely that our interviews suffer from recall and response bias, and precludes us from making an accurate interpretation of patient satisfaction. 


\section{Clinical and research implications}

These results can help guide the disposition process for both ED physicians and members of the GEM team. The high level of cognitive impairment, lack of perceived value in further assessment, and reliance on family members in this population strongly highlight the importance for clear and open communication with both patient and family. Both the family and patient need to be aware of the trajectory and often downward spiral of the geriatric syndromes prevalent in this population. ${ }^{28}$ In addition, home-based assessments should be considered when available, because this was the key facilitator identified through this work.

This study evaluated adherence to community-based evaluations, but research is needed that describes the impact of these referrals: Do patients who are compliant to referral from the ED to specialized geriatric services have improved outcomes? An in-depth examination of barriers and facilitators to attendance at communitybased evaluations is needed to inform targeted interventions to enhance adherence. Various strategies, shown to be effective in other patient populations, should be implemented and evaluated in the older ED population. ${ }^{12,13}$

\section{CONCLUSION}

Adherence of geriatric patients to outpatient specialized geriatric services is poor, with many patients outright declining referral to these evaluations prior to ED discharge. Future work should examine the adherence and efficacy of home-based assessments in a larger confirmatory setting, and focus on interventions to promote increased referral acceptance and address barriers to attendance.

Acknowledgements: We gratefully acknowledge the invaluable assistance of the geriatric emergency management nurses at the Ottawa Hospital for their assistance in patient recruitment. In addition, we thank Angela Marcantonio for her project assistance and My-Linh Tran for aiding in database management and statistical work.

Author contributions: Zachary MacDonald helped coordinate the study, collected the data, and contributed to the writing of the manuscript. Debra Eagles conceived the idea, coordinated the study, and contributed to the writing of the manuscript. Ioanna Genovezos assisted with data collection and manuscript revisions. Ian Stiell provided considerable assistance with study design and manuscript revisions. Zachary MacDonald had full access to all of the data in the study and takes responsibility for the integrity of the data and the accuracy of the data analysis.

Competing interests: None declared.

\section{SUPPLEMENTARY MATERIAL}

The supplementary material for this article can be found at https://doi.org/10.1017/cem.2019.376

\section{REFERENCES}

1. Latham LP, Ackroyd-Stolarz S. Emergency department utilization by older adults: a descriptive study. Can Geriatr 7 2014; 17(4):118-25.

2. Flynn DS, Jennings J, Moghabghab R, et al. Raising the bar of care for older people in Ontario emergency departments. Int 7 Old People Nurs 2010;5(3):219-26.

3. McCusker J, Bellavance F, Cardin S, et al. Prediction of hospital utilization among elderly patients during the 6 months after an emergency department visit. Ann Emerg Med 2000;36(5):438-45.

4. Friedman SM, Vergel de Dios J, Hanneman K. Noncompletion of referrals to outpatient specialty clinics among patients discharged from the emergency department: a prospective cohort study. CFEM 2010;12(4):325-30.

5. Wojtowicz JM, Dowling S, Nanji AM, MacLeod DB. Patient adherence with emergency department referral to a cardiovascular evaluation and risk assessment clinic. CFEM 2008;10(6):511-7.

6. Murray MJ, LeBlanc CH. Clinic follow-up from the emergency department: do patients show up? Ann Emerg Med 1996;27(1):56-8.

7. Nasreddine ZS, Phillips NA, Bedirian V, et al. The Montreal Cognitive Assessment, MoCA: a brief screening tool for mild cognitive impairment. 7 Am Geriatr Soc 2005;53(4):695-9.

8. Folstein MF, Folstein SE, McHugh PR. "Mini-mental state." A practical method for grading the cognitive state of patients for the clinician. 7 Psychiatr Res 1975;12(3):189-98.

9. Wilding L, Eagles D, Molnar F, et al. Prospective validation of the Ottawa 3DY Scale by Geriatric Emergency Management Nurses to identify impaired cognition in older emergency department patients. Ann Emerg Med 2016;67 (2):157-63.

10. Seitz DP, Chan CC, Newton HT, et al. Mini-Cog for the diagnosis of Alzheimer's disease dementia and other dementias within a primary care setting. Cochrane Database Syst Rev 2018;2:CD011415.

11. Denman SJ, Ettinger WH, Zarkin BA, et al. Short-term outcomes of elderly patients discharged from an emergency department. 7 Am Geriatr Soc 1989;37(10):937-43.

12. Guttman A, Afilalo M, Guttman R, et al. An emergency department-based nurse discharge coordinator for elder patients: does it make a difference? Acad Emerg Med 2004;11(12):1318-27. 
13. McCusker J, Dendukuri N, Tousignant P, et al. Rapid twostage emergency department intervention for seniors: impact on continuity of care. Acad Emerg Med 2003;10 (3):233-43.

14. Wrede-Sach J, Voigt I, Diederichs-Egidi H, et al. Decisionmaking of older patients in context of the doctor-patient relationship: a typology ranging from "self-determined" to "doctor-trusting" patients. Int 7 Family Med 2013;2013:478498.

15. Shipp MD, Penchansky R. Vision testing and the elderly driver: is there a problem meriting policy change? $7 \mathrm{Am}$ Optom Assoc 1995;66(6):343-51.

16. Richards D, Meshkat N, Chu J, et al. Emergency department patient compliance with follow-up for outpatient exercise stress testing: a randomized controlled trial. CFEM 2007;9 (6):435-40.

17. Kyriacou DN, Handel D, Stein AC, Nelson RR. Brief report: factors affecting outpatient follow-up compliance of emergency department patients. 7 Gen Intern Med 2005;20 (10):938-42.

18. O'Brien GM, Stein MD, Fagan MJ, et al. Enhanced emergency department referral improves primary care access. Am $\mathcal{f}$ Manag Care 1999;5(10):1265-9.

19. Thomas EJ, Burstin HR, O'Neil AC, et al. Patient noncompliance with medical advice after the emergency department visit. Ann Emerg Med 1996;27(1):49-55.

20. Straus JH, Orr ST, Charney E. Referrals from an emergency room to primary care practices at an urban hospital. $A m \mathcal{F}$ Public Health 1983;73(1):57-61.
21. Komoroski EM, Graham CJ, Kirby RS. A comparison of interventions to improve clinic follow-up compliance after a pediatric emergency department visit. Pediatr Emerg Care 1996;12(2):87-90.

22. Magnusson AR, Hedges JR, Vanko M, et al. Follow-up compliance after emergency department evaluation. Ann Emerg Med 1993;22(3):560-7.

23. Hemphill RR, Santen SA, Howell JM, Altieri MF. Follow-up compliance in febrile children: a comparison of two systems. Acad Emerg Med 1998;5(10):996-1001.

24. Field DL, Hedges JR, Arnold KJ, et al. Limitations of chest pain follow-up from an urban teaching hospital emergency department. 7 Emerg Med 1988;6(5):363-8.

25. Engel KG, Buckley BA, Forth VE, et al. Patient understanding of emergency department discharge instructions: where are knowledge deficits greatest? Acad Emerg Med 2012;19 (9):E1035-44.

26. Clarke C, Friedman SM, Shi K, et al. Emergency department discharge instructions comprehension and compliance study. CFEM 2005;7(1):5-11.

27. Hastings SN, Barrett A, Weinberger M, et al. Older patients' understanding of emergency department discharge information and its relationship with adverse outcomes. 7 Patient Safety 2011;7(1):19-25.

28. Huang CC, Lee JD, Yang DC, et al. Associations between geriatric syndromes and mortality in community-dwelling elderly: results of a national longitudinal study in Taiwan. $\mathcal{F}$ Am Med Dir Assoc 2017;18(3):246-51. 